\title{
Trimethoprim-sulfamethoxazole induced circulatory shock in a human immunodeficiency virus uninfected patient: a case report and review
}

\author{
Patricia Liu ${ }^{1 *}$ (D), Gregory P. Ranches ${ }^{2}$ and Jeffrey A. Gold ${ }^{2}$
}

\begin{abstract}
Background: Severe systemic reactions resembling septic shock have been described following trimethoprimsulfamethoxazole (TMP-SMX) administration. Nearly all cases described in the literature occurred in HIV-infected patients.

Case presentation: We present a 42-year-old woman with a history of systemic lupus erythematosus (SLE) who was admitted to the Intensive Care Unit (ICU) twice with fever and circulatory shock after taking a dose of TMPSMX 800-160 mg. She had no respiratory distress, urticarial rash or eosinophilia on presentation. Infectious workup during both admissions was negative and treatment with antibiotics, steroids and vasopressors was de-escalated with clinical improvement. She was found to be HIV negative, however, labs revealed a low CD4+ count.

Conclusions: TMP-SMX can rarely result in a severe, non-anaphylactic circulatory shock; if initially unrecognized, patients may undergo repeat drug exposure with an associated high morbidity risk. While more commonly reported in HIV individuals, this case demonstrates that TMP-SMX related circulatory shock can occur in a HIV negative patient.
\end{abstract}

Keywords: Adverse drug reaction, Shock, HIV, CD4+ count, IL-6, Trimethoprim-sulfamethoxazole

\section{Background}

Adverse drug reactions to antibiotics complicate the management of any infection. Trimethoprim-sulfamethoxazole (TMP-SMX) is generally well tolerated in non-human immunodeficiency virus (HIV) infected patients, however serious adverse reactions occur at an approximate rate of $3-5 \%$ [1]. More recently, severe systemic reactions resembling septic shock have been described following TMPSMX administration [2-4]. Nearly all cases described in the literature occurred in HIV-infected patients, with the exception of two HIV-negative cases [5]. Here we report a case of a HIV-negative patient who twice developed circulatory shock following exposure to TMP-SMX.

\footnotetext{
* Correspondence: liup@ohsu.edu

1 Department of Internal Medicine, Oregon Health \& Science University, VA P-3-GP1, block 4, 3181 SW Sam Jackson Park Rd, Portland, OR 97239-3098, USA

Full list of author information is available at the end of the article
}

\section{Case presentation}

A 42-year-old woman with history of SLE on hydroxychloroquine, mycophenolate and prednisone, complicated by pancytopenia, presented with severe back pain $30 \mathrm{~min}$ after taking oral TMP-SMX $800-160 \mathrm{mg}$ for paronychia. She was found to be febrile to $39.1^{\circ} \mathrm{C}$, hypotensive at $88 / 63 \mathrm{mmHg}$, and tachycardic at 107 BPM. Laboratory testing revealed a white blood cell (WBC) count of $8.63 \times 10^{3} / \mathrm{uL}(97.3 \%$ neutrophils, $0.1 \%$ eosinophils, $0.2 \%$ lymphocytes, with a baseline WBC of $2 \times 10^{3} / \mathrm{uL}$ ), lactate $2.3 \mathrm{mmol} / \mathrm{L}$ and creatinine of $1.3 \mathrm{mg} /$ $\mathrm{dL}$ (baseline $0.7 \mathrm{mg} / \mathrm{dL}$ ) (Table 1). HIV ELISA was negative but the CD4+ count was low at 64 cells/uL. Computed tomography (CT) angiogram of the chest showed no evidence of pulmonary embolus or infection and urinalysis was not suggestive of infection. Physical exam was significant for diffusely erythematous and warm skin without macules, papules, or urticaria. There were no

(c) The Author(s). 2018 Open Access This article is distributed under the terms of the Creative Commons Attribution 4.0 International License (http://creativecommons.org/licenses/by/4.0/), which permits unrestricted use, distribution, and 
Table 1 Timeline of Presentations and Presenting Vitals and Labs

\begin{tabular}{|c|c|c|}
\hline & May 2017 & July 2016 \\
\hline \multicolumn{3}{|l|}{ Vitals } \\
\hline Blood Pressure (mmHg) & $88 / 63$ & $79 / 45$ \\
\hline Heart Rate (BPM) & 107 & 121 \\
\hline Temperature $\left({ }^{\circ} \mathrm{C}\right)$ & 39.1 & 39.0 \\
\hline Respiratory Rate & 22 & 23 \\
\hline $\mathrm{O}_{2}$ Saturation & $96 \%$ on Room Air & 97\% on Room Air \\
\hline \multicolumn{3}{|l|}{ Labs } \\
\hline \multirow[t]{2}{*}{ Basic Chemistry Panel } & \begin{tabular}{l|l|l}
140 & 115 & 23 \\
\end{tabular} & \begin{tabular}{l|l|l}
139 & 112 & $28 / 76$ \\
\end{tabular} \\
\hline & \begin{tabular}{c|c|c}
4.0 & 18 & 1.30 \\
(baseline Cr: 0.7$)$ &
\end{tabular} & 3.9 \\
\hline Complete Blood Count & $\begin{array}{l}8.6>\frac{10.4}{30.9}>99 \\
97.3 \% \text { neutrophils } \\
\text { 0.1\% eosinophils } \\
\text { 0.2\% lymphocytes } \\
\text { (baseline WBC: } 2 \times 10^{3} / \mathrm{LL} \text { ) }\end{array}$ & $\begin{array}{l}10.9>\frac{10.2}{30.3} \\
95.5 \% \text { neutrophils } \\
\text { 0.6\% lymphocytes } \\
\text { 0.5\% eosinophils }\end{array}$ \\
\hline Lactate & $2.3 \mathrm{mmol} / \mathrm{L}$ & $1.2 \mathrm{mmol} / \mathrm{L}$ \\
\hline HIV Elisa & Negative & Not checked \\
\hline CD4+ Count & 64 cells/uL & Not checked \\
\hline Infectious Work Up & $\begin{array}{l}\text { CTA chest } \\
\text { Urine cultures } \\
\text { Blood cultures }\end{array}$ & $\begin{array}{l}\text { CT head } \\
\text { CT cervical, thoracic and lumbar spine } \\
\text { CT abdomen and pelvis } \\
\text { Echocardiogram } \\
\text { Urine cultures } \\
\text { Blood cultures }\end{array}$ \\
\hline
\end{tabular}

other focal findings on physical exam. The patient was initially managed with aggressive $80 \mathrm{~mL} / \mathrm{kg}$ intravenous (IV) fluid resuscitation, norepinephrine, broad-spectrum antibiotics (IV vancomycin and IV piperacillin-tazobactam), and stress dose steroids (hydrocortisone $50 \mathrm{mg}$ IV every 6 h). Her hypotension resolved quickly over the first $36 \mathrm{~h}$ of admission. Over the following 3 days blood and urine cultures remained negative and steroids, vasopressors and antibiotics were discontinued without recurrence of hypotension. Additional infectious work up, including hepatitis $\mathrm{B}$, hepatitis $\mathrm{C}$ and toxoplasma, were negative. The patient was discharged home on hospital day four with pneumocystis jirovecii pneumonia (PJP) prophylaxis with atovaquone.

Ten months prior, the patient had a similar presentation several hours after taking her second dose of oral TMP-SMX 800-160 mg, which was prescribed for an abscess of the mons pubis. On presentation, she was hypotensive, tachycardic and febrile. Laboratory testing revealed a WBC of $10.9 \times 10^{3} / \mathrm{uL}(95.5 \%$ neutrophils, $0.6 \%$ lymphocytes and $0.5 \%$ eosinophils), acute kidney injury (creatinine $1.1 \mathrm{mg} / \mathrm{dL}$ ) and lactate of $1.2 \mathrm{mmol} / \mathrm{L}$. She was treated similarly for presumed septic shock.
Work-up for infectious etiologies including blood and urine cultures, CT imaging of head, spine and abdomen as well as an echocardiogram was unrevealing. She was weaned off vasopressor support within $24 \mathrm{~h}$. Her steroids and antibiotics were discontinued within $72 \mathrm{~h}$ with clinical improvement and she was discharged home with the diagnosis of septic shock with unknown etiology.

\section{Discussion and conclusions}

TMP-SMX causes serious adverse drug reactions (ADR) in $40-65 \%$ of $\mathrm{HIV}$-infected persons and only $3-5 \%$ in non-infected persons [6-9]. Previous studies demonstrated that rates of ADRs correlate with HIV viral load and that the highest rates of some ADRs occur when CD4+ counts fall below 100 cells/uL [10, 11]. More recently, severe systemic reactions resembling septic shock have been described following TMP-SMX administration. To our knowledge, this is the first reported case of a severe systemic reaction to TMP-SMX in an HIV-negative, CD4+ lymphocytopenic patient. Although HIV viral load has historically been the predominant risk factor, our case raises the question of whether low CD4+ cell count, which can occur independent of HIV in 


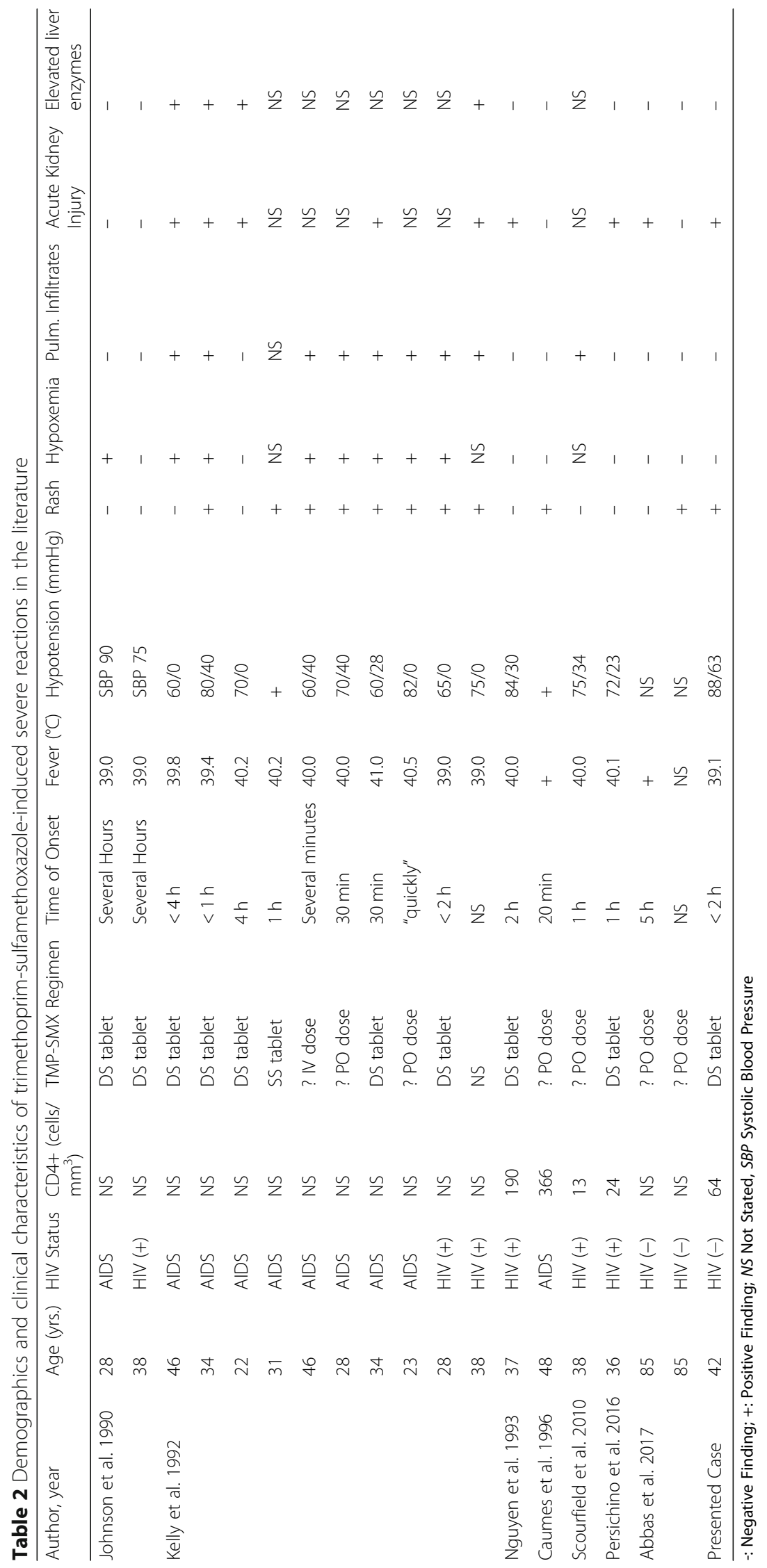


connective tissue diseases or due to an adverse effect of immunosuppressive medications, could be associated with TMP-SMX induced circulatory shock.

Other etiologies of the patient's shock were considered, such as sepsis, adrenal insufficiency and anaphylaxis. Although she was prescribed TMP-SMX for an infection both times (mons pubis abscess and paronychia), they were minor infections. Other data against septic shock include an otherwise negative infectious work up, negative lactate and rapid resolution of shock. She was given stress dose steroids given the extent of her hypotension but they were quickly tapered without recurrence of shock, making adrenal insufficiency unlikely. Lastly, she did not have urticaria, eosinophilia, laryngeal edema or bronchospasms that are typical for anaphylactic shock. While TMP-SMX has many important drug-drug interactions to consider, there are no established reactions between TMP-SMX and the patient's medication list to explain this reaction.

We identified 17 cases in the literature of TMP-SMX induced circulatory shock similar to that noted in our patient (Table 2) $[2-5,12-14]$. Fifteen of the 17 cases were in $\mathrm{HIV}+$ patients. Including the case presented here, all 18 patients experienced an abrupt onset of fever and hypotension within minutes to hours after the administration of TMP-SMX. Ten of the 18 patients were noted to have a rash; nine of which were described as diffusely erythematous and one that was described as urticarial. In terms of end organ damage, it appears that acute kidney injury is the most common, occurring in 9 of the 18 patients. Hypoxemia, pulmonary infiltrates and elevated liver enzymes were also reported in some cases.

The mechanism behind TMP-SMX induced circulatory shock remains unclear. At present, whether this reaction represents a form of immune activation, cellular toxicity or non-specific immune reaction is unclear. Nguyen and colleagues have argued that TMPSMX induced shock is likely not a traditional anaphylactic reaction based on the lack of TNF- $\alpha$ and IgE elevation upon re-challenge of a HIV+ patient with known TMP-SMX induced shock [12]. Instead they observed a marked rise and fall of IL- 6 temporally associated with the episode of shock. Interestingly, IL-6 has also been implicated in TMP-SMX induced aseptic meningitis and macrophage activation syndrome [1517]. As IL-6 is also known to be elevated in septic shock associated with bacterial infections, one hypothesis to consider is whether TMP-SMX induced shock and septic shock share a final downstream mechanism [18]. Further investigation into the cytokine profile and cellular responses involved in TMP-SMX induced shock in warranted.

It is also not clear whether trimethoprim or sulfamethoxazole, or both, are drivers of the shock reaction; many hypotheses exist. Some in vitro studies suggest that incubation of the hydroxylamine of sulfamethoxazole with HIV-infected cells produced concentration-dependent toxicity that is significantly greater than in non-HIV infected cells [10]. This is one possible explanation for the increased rates of serious sulfonamide adverse drug reactions among patients with HIV. Trimethoprim, an inhibitor of dihydrofolate reductase, has been proposed to cause aseptic meningitis [19]. One study observed higher in vitro IL-6 production in cells of patients with trimethoprim induced systemic adverse reactions compared to trimethoprim tolerant patients [16]. Trimethoprim can also inhibit renal tubular secretion of potassium and creatinine, thus leading to adverse events such as hyperkalemia and acute tubular necrosis [20]. However, to date, there are no studies that implicate trimethoprim alone in the development of hypotension or shock.

There have been few case reports and series describing shock in reaction to TMP-SMX, overall, cases may be under reported or lack complete clinical datasets. To our knowledge, this case is the third described in a patient who is HIV negative. TMP-SMX induced shock is not a widely recognized phenomenon, but is particularly important to consider in lymphopenic patients with circulatory shock and recent TMP-SMX administration. Adding TMP-SMX to the allergy list in these patients is of utmost importance in order to prevent future recurrences.

\section{Abbreviations \\ ADR: Adverse Drug Reaction; CT: Computed Tomography; ELISA: Enzyme Linked Immunosorbent Assay; HIV: Human Immunodeficiency Virus; ICU: Intensive Care Unite; IL: Interleukin; PJP: Pneumocystis Jirovecii Pneumonia; SLE: Systemic Lupus Erythematous; TMP-SMX: Trimethoprim-sulfamethoxazole; TNF: Tumor Necrosis Factor; WBC: White Blood Cell}

\section{Acknowledgements}

No other acknowledgements.

Funding

No funding sources to report.

Availability of data and materials

Not applicable.

\section{Authors' contributions}

PL drafted the manuscript. GPR revised the manuscript for important intellectual content. JAG revised the manuscript for important intellectual content and gave final approval of the version to be published. All authors read and approved the final manuscript.

Ethics approval and consent to participate Not applicable.

\section{Consent for publication}

Written and verbal consent from the patient has been obtained. As stated in the instructions, a consent form has not been included on submission but is available for request.

Competing interests

The authors declare that they have no competing interests. 


\section{Publisher's Note}

Springer Nature remains neutral with regard to jurisdictional claims in published maps and institutional affiliations.

\section{Author details}

'Department of Internal Medicine, Oregon Health \& Science University, VA P-3-GP1, block 4, 3181 SW Sam Jackson Park Rd, Portland, OR 97239-3098, USA. ${ }^{2}$ Division of Pulmonary and Critical Care Medicine, Oregon Health \& Science University, Portland, Oregon, USA.

Received: 5 August 2018 Accepted: 7 November 2018

Published online: 20 November 2018

\section{References}

1. Jick H, Derby LE. A large population-based follow-up study of trimethoprimsulfamethoxazole, trimethoprim, and cephalexin for uncommon serious drug toxicity. Pharmacotherapy. 1995;15(4):428-32

2. Kelly JW, Dooley DP, Lattuada CP, Smith CE. A severe, unusual reaction to trimethoprim-sulfamethoxazole in patients infected with human immunodeficiency virus. Clin Infect Dis. 1992:14(5):1034-9.

3. Caumes E, Guermonprez G, Winter C, Katlama C, Bricaire F. A lifethreatening adverse reaction during trimethoprim-sulfamethoxazole desensitization in a previously hypersensitive patient infected with human immunodeficiency virus. Clin Infect Dis. 1996;23(6):1313-4.

4. Johnson MP, Goodwin SD, Shands JW Jr. Trimethoprim-sulfamethoxazole anaphylactoid reactions in patients with AIDS: case reports and literature review. Pharmacotherapy. 1990;10(6):413-6.

5. Farrukh Abbas MP, Abbas K, Shah P, Gurel M. Trimethoprimsulfamethoxazole (TMP-SMX) induced severe systemic reaction. J Pulm Respir Med. 2017;7(1).

6. Coopman SA, Johnson RA, Platt R, Stern RS. Cutaneous disease and drug reactions in HIV infection. N Engl J Med. 1993;328(23):1670-4.

7. Jung AC, Paauw DS. Management of adverse reactions to trimethoprimsulfamethoxazole in human immunodeficiency virus-infected patients. Arch Intern Med. 1994;154(21):2402-6.

8. Kovacs JA, Hiemenz JW, Macher AM, et al. Pneumocystis carinii pneumonia: a comparison between patients with the acquired immunodeficiency syndrome and patients with other immunodeficiencies. Ann Intern Med. 1984;100(5):663-71.

9. Medina I, Mills J, Leoung G, et al. Oral therapy for pneumocystis carini pneumonia in the acquired immunodeficiency syndrome. A controlled trial of trimethoprim-sulfamethoxazole versus trimethoprim-dapsone. N Engl J Med. 1990;323(12):776-82.

10. Rieder MJ, Krause R, Bird IA, Dekaban GA. Toxicity of sulfonamide-reactive metabolites in HIV-infected, HTLV-infected, and noninfected cells. J Acquir Immune Defic Syndr Hum Retrovirol. 1995;8(2):134-140.

11. Rabaud C, Charreau I, Izard S, et al. Adverse reactions to cotrimoxazole in HIV-infected patients: predictive factors and subsequent HIV disease progression. Scand J Infect Dis. 2001;33(10):759-64

12. Nguyen BY, Landucci DL, Cunnion RE, Yarchoan R, Walker RE. A case of hyperdynamic shock caused by trimethoprim-sulfamethoxazole in which no tumor necrosis factor or features of anaphylaxis were detected. Clin Infect Dis. 1993;17(5):885-7.

13. Scourfield A, Tan LK, Nelson M. Severe septic-shock like reaction to cotrimoxazole in an HIV-positive man. Int J STD AIDS. 2010;21(7):521-3.

14. Persichino J, Sutjita M. Anaphylactic-like reaction from trimethoprimsulfamethoxazole in a patient with AIDS. Int J STD AIDS. 2016;27(7): 595-7.

15. Antonen J, Hulkkonen J, Pasternack A, Hurme M. Interleukin 6 may be an important mediator of trimethoprim-induced systemic adverse reaction resembling aseptic meningitis. Arch Intern Med. 2000;160(13):2066-7.

16. Antonen J, Saha H, Hulkkonen J, Lumio J, Pasternack A, Hurme M. Increased in vitro production of interleukin 6 in response to trimethoprim among persons with trimethoprim induced systemic adverse reactions. J Rheumatol. 1999:26(12):2585-90.

17. Vernier M, Million M, Laugier D, Le Treut T, Brouqui P, Botelho-Nevers E. Macrophage activation syndrome associated with co-trimoxazole. Med Ma Infect. 2013;43(3):128-30.

18. Calandra T, Gerain J, Heumann D, Baumgartner JD, Glauser MP. High circulating levels of interleukin- 6 in patients with septic shock: evolution during sepsis, prognostic value, and interplay with other cytokines. The Swiss-Dutch J5 immunoglobulin study group. Am J Med. 1991;91(1):23-9.

19. Harrison MS, Simonte SJ, Kauffman CA. Trimethoprim-induced aseptic meningitis in a patient with AIDS: case report and review. Clin Infect Dis. 1994;19(3):431-4.

20. Greenberg S, Reiser IW, Chou SY, Porush JG. Trimethoprim-sulfamethoxazole induces reversible hyperkalemia. Ann Intern Med. 1993;119(4):291-5.

\section{Ready to submit your research? Choose BMC and benefit from:}

- fast, convenient online submission

- thorough peer review by experienced researchers in your field

- rapid publication on acceptance

- support for research data, including large and complex data types

- gold Open Access which fosters wider collaboration and increased citations

- maximum visibility for your research: over $100 \mathrm{M}$ website views per year

At $\mathrm{BMC}$, research is always in progress.

Learn more biomedcentral.com/submissions 